\title{
Sakubitril/valsartan potansiyel endikasyonlarına ilişkin gelecekten beklentiler nelerdir?
}

\author{
Dr. Mehmet Birhan Yılmaz
}

Dokuz Eylül Üniversitesi Tıp Fakültesi, Kardiyoloji Anabilim Dalı, İzmir

Sakubitril/valsartan için, var olan endikasyon alanında yapılabilecek genişlemeler yanında, yakın gelecekte beş temel vizyonun hedeflendiği düşünülmektedir: ${ }^{[1]}$ Post-AMI endikasyon, sistemik hastalıklarla indüklenmiş sağ kalp yetersizliğinde kullanım, kardiyoonkoloji'de kullanımı, erektil disfonksiyondaki yeri, ileri KY'deki yeri (destek cihazı implante edilmiş hastalarda). Bu alt alanlar, potansiyel endikasyona dair çalışmasıyla birlikte ele alınmıştır.

"Prospective ARNI vs ACE Inhibitor Trial to DetermIne Superiority in Reducing Heart Failure Events After MI” (PARADISE-MI) çalışması (NCT02924727), sakubitril/valsartanın (2x200 mg), AMI sonrası sistolik işlev bozukluğu ve/veya pulmoner konjesyon bulguları olan ve önceden KY öyküsü olmayan hastalarda etkin dozda ramipril ile $(2 \times 5 \mathrm{mg})$ kıyaslandığ 1 , hali hazırda hasta alımı tamamlanmış, sonlanımların beklendiği bir Faz III araştırmadır ve yakın zamanda sonuçların açıklanması beklenmektedir. Çalışmanın primer sonlanım noktası kardiyovasküler ölüm, kalp yetersizliğine bağlı hospitalizasyon veya ayaktan KY başvurusudur. Mevcut çalışma, sakubitril/valsartanın endikasyonunu genişletme ve k1lavuz önerisini Sınıf 1A düzeyine taşıma potansiyeli açısından önemlidir.

Kardiyoonkoloji, KY'nin ilgi çekici ve giderek büyüyen alanlarından birisini oluşturmaktadır. Öte yandan, RAAS blokerlerinin kemoterapi ile indüklenmiş kardiyotoksisiteye karşı koruyucu etkileri olduğuna dair literatürde yayınlar bulunmaktadır. [2,3] "Prevention of Cardiac Dysfunction During Breast Cancer Therapy" (PRADAII) çalışmasında (NCT03760588), meme kanseri sebebiyle antrasiklin içeren kemoterapi kullanacak hastalarda eş zamanlı sakubitril/valsartan kullanımının sine-MR ile ölçülen kardiyak işlev bozukluğuna etkisi araştırılmaktadır. Araştırmada aynı zamanda, kardiyak görüntüleme, biyobelirteç, işlevsel kapasite ve yaşam kalitesi ölçeği değerlendirme- leri de yer almaktadır. Bu ve benzer araştırmalardan elde edilen sonuçlarla sakubitril/valsartanın kardiyoonkolojik korumada yeni bir endikasyon alma ihtimali bulunmaktadır.

Sakubitril/valsartan, kronik DEF-KY'si olan hastalarda sağ kalp işlevini iyileştirebilir. ${ }^{[4]}$ Sakubitril/valsartanın bağ dokusu hastalığı sebebiyle sağ KY gelişmiş hastalarda kullanımını inceleyen "Effect of Sacubitril/ Valsartan on Reduced Right Ventricular Ejection Fraction in Patients With CTD" (EARLY-MYO-CTD) ça1ısması (NCT04197050), sağ kalp yetersizliğine yönelik spesifik odaklanma sebebiyle ilginç bir çalışmadır. Çalışmada, bağ dokusu hastalığı sebebiyle (skleroderma vs.) sağ kalp yetersizliği gelişmiş hastalarda sakubitril/valsartanın 6 dakika yürüme testi, miyokardiyal fibrosis üzerine etkisi araştırılacaktır.

Chandra A ve ark. tarafından sakubitril/valsartanın yaşam kalitesine, özellikle cinsel yaşama dair olumlu etkilerinin bildirildiği PARADIGM-HF çalışmasının alt grup analizi çok dikkat çekmiştir. ${ }^{[5]}$ "COmparing arNi and Ace For Improving Erectile Dysfunction in mEN With reduCed Ejection Fraction Heart Failure" (CONFIDENCE-HF) çalışması da (NCT03917459) bu konuyu direkt olarak hedefleyen, kronik DEFKY'si olan ve hafif-orta düzeyde erektil disfonksiyonu olan erkek hastalarda enalapril tedavisini sakubitril/valsartanla 3 aylık sürede erektil fonksiyon skor değişimi açısından kıyaslayan bir araştırmadır. Araştırmanın olumlu çıkması durumunda erkek hastaların kullanımında olumlu bir motivasyon yaşanacağı düşünülebilir.

Ventrikül destek cihazları, ileri evre KY hastalarında endike olan pahalı tedavi seçenekleridir. ${ }^{[6] ~ " S a-~}$ cubitril/valsartan in Left Ventricular Assist Device Recipients" (ENVAD-HF), sakubitril/valsartanın ileri evre KY'si olup destek cihazı implante edilmiş hastalardaki etkinliğini araştıran çalışmalardan birisidir. ENVAD-HF çalışmasında (NCT04103554), en son ç1-

Yazışma adresi: Dr. Mehmet Birhan Yılmaz. Dokuz Eylül Üniversitesi Tıp Fakültesi, 
kan sol ventrikül destek cihazı olan HeartMate3 implante edilmiş hastalarda sakubitril/valsartan enalapril ile, tüm nedenlere bağlı ölüm, sağ KY gelişimi, kanama olayları, böbrek işlevinde kötüleşme, hiperkalemi ve hipotansiyon açısından kıyaslanacaktır. Kardiyak geri dönüşümün hayal edildiği, hipotansiyonun göreceli olarak daha az bir sorun olduğu günümüz destek sistemleri teknolojisinde, yüksek doz sakubitril/valsartan ile ileri evre KY hastalarında sağlanacak başarılı bir sonuç tüm paydaşlar açısından yüz güldürüicü olma potansiyeline sahiptir.

\section{Kaynaklar}

1. Kuchulakanti PK. ARNI in cardiovascular disease - current evidence and future perspectives. Future Cardiol. 2020 Apr 22. doi: 10.2217/ fca-2019-0089. Epub ahead of print.
2. Gulati G, Heck SL, Ree AH, Hoffmann P, Schulz-Menger J, Fagerland MW, et al. Prevention of cardiac dysfunction during adjuvant breast cancer therapy (PRADA): a $2 \times 2$ factorial, randomized, placebo-controlled, double-blind clinical trial of candesartan and metoprolol. Eur Heart J 2016;37:1671-80.

3. Gupta V, Kumar Singh S, Agrawal V, Bali Singh T. Role of ACE inhibitors in anthracycline-induced cardiotoxicity: A randomized, doubleblind, placebo-controlled trial. Pediatr Blood Cancer 2018;65:e27308.

4. Correale M, Mallardi A, Mazzeo P, Tricarico L, Diella C, Romano $\mathrm{V}$, et al. Sacubitril/valsartan improves right ventricular function in a real-life population of patients with chronic heart failure: The Daunia Heart Failure Registry. Int J Cardiol Heart Vasc 2020;27:100486.

5. Chandra A, Lewis EF, Claggett BL, Desai AS, Packer M, Zile MR, et al. Effects of Sacubitril/Valsartan on Physical and Social Activity Limitations in Patients With Heart Failure: A Secondary Analysis of the PARADIGM-HF Trial. JAMA Cardiol 2018;3:498-505.

6. Potapov EV, Antonides C, Crespo-Leiro MG, Combes A, Färber G, Hannan MM, et al. 2019 EACTS Expert Consensus on long-term mechanical circulatory support. Eur J Cardiothorac Surg 2019;56:230-70. 